\title{
Synthesis, Characterization and Evaluation of a Novel BODIPY Derivative as a Colorimetric Chemosensor for $\mathrm{Fe}^{3+}$ Recognition ${ }^{+}$
}

\author{
Raquel C. R. Gonçalves, Sónia C. S. Pinto, Susana P. G. Costa and M. Manuela M. Raposo * \\ Centre of Chemistry, University of Minho, Campus of Gualtar, 4710-057 Braga, Portugal; \\ raquelrainha10@hotmail.com (R.C.R.G.); soniapinto4197@gmail.com (S.C.S.P.); \\ spc@quimica.uminho.pt (S.P.G.C.) \\ * Correspondence: mfox@quimica.uminho.pt \\ + Presented at the 23rd International Electronic Conference on Synthetic Organic Chemistry, \\ 15 November 2019-15 December 2019; Available online: https://ecsoc-23.sciforum.net/.
}

Published: 14 November 2019

\begin{abstract}
A 4,4-difluoro-4-bora-3a,4a-diaza-s-indacene (BODIPY) derivative functionalized with a formyl group at position 2 was synthesized in $57 \%$ yield. The compound was characterized by ${ }^{1} \mathrm{H}$ and ${ }^{13} \mathrm{C}$ Nuclear Magnetic Resonance (NMR) spectroscopy and mass spectrometry. The photophysical characterization was carried out by means of absorption and fluorescence spectroscopies in acetonitrile solutions. The BODIPY derivative showed an absorption band at 492 $\mathrm{nm}$ and an emission band at $506 \mathrm{~nm}$. A preliminary evaluation of the recognition ability of the BODIPY derivative was investigated in the presence of several cations with environmental and biomedical relevance. A highly selective colorimetric response was obtained for $\mathrm{Fe}^{3+}$.
\end{abstract}

Keywords: BODIPY; colorimetric chemosensor; $\mathrm{Fe}^{3+}$; synthesis

\section{Introduction}

BODIPY derivatives have been proving to be a key class of compounds as a tool for a wide range of research fields. Among the diverse applications of BODIPYs, the development of derivatives owning the ability to recognize and detect small organic molecules and metal ions have received great attention in the last years. Moreover, the BODIPY core can be chemically modified in order to improve the optical properties or add new functionalities as chemosensors, for example, insertion of receptor groups selective to analytes. There are diverse cations with biological and environmental relevance, such as $\mathrm{Fe}^{3+}$ as an important metal ion in several physiological processes involving electron transfer and also as an enzymatic cofactor for oxygen transport, DNA synthesis, etc. On the other hand, the accumulation of iron in the central nervous system has been implicated in a number of diseases. Therefore, the design of molecular systems for recognition of cations with "naked-eye" detection is an attractive goal [1-4].

In continuation of our research group's investigation developed in the field of chromofluorogenic sensors [5-8], we report in this work the synthesis, characterization, and evaluation of a novel BODIPY derivative as a colorimetric chemosensor for $\mathrm{Fe}^{3+}$ recognition in acetonitrile solution. 


\section{Experimental Section}

\subsection{Methods and Materials}

NMR spectra were obtained on a Bruker Avance III 400 at an operating frequency of $400 \mathrm{MHz}$ for ${ }^{1} \mathrm{H}$ and $100.6 \mathrm{MHz}$ for ${ }^{13} \mathrm{C}$, using the solvent peak as an internal reference. The solvents are indicated in parenthesis before the chemical shift values ( $\delta$ relative to tetramethylsilane (TMS)). Peak assignments were made by comparison of chemical shifts, peak multiplicities, and $J$ values, and were supported by spin decoupling-double resonance and bidimensional heteronuclear techniques. Mass spectrometry analyses were performed at the "C.A.C.T.I. - Unidad de Espectrometria de Masas" at the University of Vigo, Spain. All reagents were purchased from Sigma-Aldrich, Acros and Fluka and used as received. Precursor BODIPY 1 was synthesized as previously reported [8]. Thin-layer chromatography (TLC) analysis was carried out on $0.25 \mathrm{~mm}$ thick precoated silica plates (Merck Fertigplatten Kieselgel 60F254), and the spots were visualized under ultraviolet (UV) light. Chromatography on silica gel was carried out on Merck Kieselgel (230-400 mesh). The UV-visible absorption spectra were obtained using a Shimadzu UV/2501PC spectrophotometer. Fluorescence spectra were collected using a FluoroMax- 4 spectrofluorometer. The relative fluorescence quantum yields were determined by using a $1 \times 10^{-5} \mathrm{M}$ solution of Rhodamine $6 \mathrm{G}$ in ethanol as a standard $\left(\Phi_{F}=0.95\right)[9,10]$.

\subsection{Synthesis of BODPY Derivative 2}

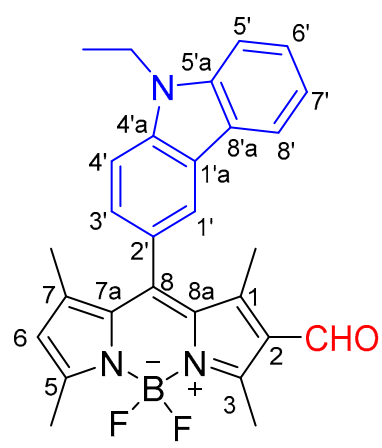

A mixture of $\mathrm{N}, \mathrm{N}$-dimethylformamide (DMF) $(23 \mathrm{mmol})$ and $\mathrm{POCl}_{3}(18.2 \mathrm{mmol})$ was stirred for $5 \mathrm{~min}$ at $0{ }^{\circ} \mathrm{C}$ under a $\mathrm{N}_{2}$ atmosphere. Once the mixture reached room temperature, it was allowed to stir for $30 \mathrm{~min}$. Then, BODIPY precursor $1(0.127 \mathrm{mmol})$ dissolved in dichloroethane $(7 \mathrm{~mL})$ was added dropwise with stirring. The reaction mixture was then heated for $2 \mathrm{~h}$ at $50{ }^{\circ} \mathrm{C}$. After cooling, the solution was poured slowly into $40 \mathrm{~mL}$ of saturated sodium bicarbonate solution at $0{ }^{\circ} \mathrm{C}$ and stirred for $30 \mathrm{~min}$ at room temperature. Ethyl acetate $(5 \mathrm{~mL})$ was added to the reaction mixture, and the resulting organic layer separated and washed with water $(2 \times 50 \mathrm{~mL})$. The organic layer was dried with anhydrous $\mathrm{MgSO}_{4}$, filtered, and the solvent was evaporated. The crude residue was purified through a silica gel chromatography column, using dichloromethane as eluent. The product was obtained as a dark red solid $(0.030 \mathrm{~g}, 57 \%)$.

${ }^{1} \mathrm{H}$ RMN (400 MHz, $\left.\mathrm{CDCl}_{3}\right): \delta=1.37\left(\mathrm{~s}, 3 \mathrm{H}, \mathrm{CH}_{3}-7\right), 1.37\left(\mathrm{t}, J=7.2 \mathrm{~Hz}, 3 \mathrm{H}, \mathrm{N}\left(\mathrm{CH}_{2} \mathrm{CH}_{3}\right), 1.61(\mathrm{~s}, 3 \mathrm{H}\right.$, $\left.\mathrm{CH}_{3}-1\right), 2.65$ (s, 3H, CH3-5), 2.86 (s, 3H, CH3-3), 4.45 (q, J = 7.2 Hz, 2H, N( $\left.\mathrm{CH}_{2} \mathrm{CH}_{3}\right), 6.15$ (s, 1H, H-6), 7.27-7.35 (m, 2H, H-3' e H-4'), 7.52-7.58 (m, 3H, H-6', H-7' e H-8'), 8.00 (s, 1H, H-1'), 8.08 (d, J = 7.6 Hz, $\left.1 \mathrm{H}, \mathrm{H}-5^{\prime}\right), 10.01$ (s, 1H, CHO) ppm.

${ }^{13} \mathrm{C}$ NMR $\left(100.6 \mathrm{MHz}, \mathrm{CDCl}_{3}\right): \delta=11.85,13.04,13.8,15.06,15.14,37.87,108.94,109.16,119.50,119.88$, $120.62,122.46,123.59,123.75,124.15,124.91,126.30,126.56,130.65,134.88,135.82,140.18,143.13$, $145.15,147.52,156.22,161.09,185.96 \mathrm{ppm}$.

MS (ESI) $m / z(\%): 471\left([\mathrm{M}+2]^{+\bullet}, 31\right), 470\left([\mathrm{M}+1]^{+\bullet}, 100\right), 469\left([\mathrm{M}]^{+\bullet}, 23\right), 437(9), 393(8), 349(6), 305$ (3), 242 (52); HRMS (ESI) $\mathrm{m} / \mathrm{z}:[\mathrm{M}+1]^{+\bullet}$ for $\mathrm{C}_{28} \mathrm{H}_{27} \mathrm{BF}_{2} \mathrm{~N}_{3} \mathrm{O}$ calcd. 470.2210; found 470.2225. 


\subsection{Chemosensing Studies of BODIPY Derivative $\mathbf{2}$ and Spectrophotometric Titration}

Evaluation of BODIPY derivative 2 as a colorimetric chemosensor was carried out in the presence of several cations $\left(\mathrm{Ag}^{+}, \mathrm{K}^{+}, \mathrm{Li}^{+}, \mathrm{Pb}^{2+}, \mathrm{Mn}^{2+}, \mathrm{Cd}^{2+}, \mathrm{Cu}^{2+}, \mathrm{Cl}^{2+}, \mathrm{Pd}^{2+}, \mathrm{Ni}^{2+}, \mathrm{Ca}^{2+}, \mathrm{Hg}^{2+}, \mathrm{Zn}^{2+}, \mathrm{Fe}^{2+}\right.$, $\mathrm{Fe}^{3+}$ and $\left.\mathrm{Al}^{3+}\right)$ with environmental and biomedical relevance. Solutions of the compound $\left(1 \times 10^{-5} \mathrm{M}\right)$ and solutions of cations under study $\left(1 \times 10^{-2} \mathrm{M}\right)$ were prepared in acetonitrile. A preliminary study was carried out by addition of up to 50 equivalents of each cation to the solution of BODIPY derivative in acetonitrile.

The spectroscopic study of BODIPY derivative 2 was performed in the presence of $\mathrm{Fe}^{3+}$ as a result of the preliminary study, which revealed the selectivity towards this cation. The solution of the BODIPY derivative $\left(1 \times 10^{-5} \mathrm{M}\right)$ and the solution of the cation under study $\left(1 \times 10^{-2} \mathrm{M}\right)$ were prepared in acetonitrile. The spectrophotometric titration was performed by the sequential addition of $\mathrm{Fe}^{3+}$ solution to the BODIPY derivative solution.

\section{Results and Discussion}

\subsection{Synthesis of BODIPY Derivative 2}

The synthesis of BODIPY derivative $\mathbf{2}$ was obtained through Vilsmeier-Haack formylation of BODIPY precursor 1, meso-substituted with a carbazole group, using dimethylformamide and phosphorylchloride as Vilsmeier reagent in 1,2-dichloroethane (Scheme 1). The pure BODIPY derivative functionalized with a formyl group was obtained as a dark red solid in $57 \%$ yield.
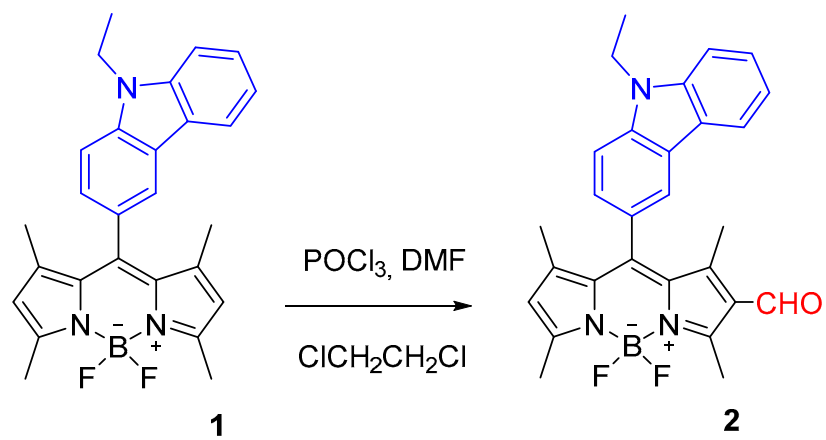

Scheme 1. Synthesis of BODIPY derivative 2.

The presence of a formyl group at position 2 of the BODIPY core was confirmed by ${ }^{1} \mathrm{H}$ NMR spectroscopy, with the appearance of a singlet at $\delta 10.01 \mathrm{ppm}$.

\subsection{Photophysical Characterization of BODIPY Derivative $\mathbf{2}$}

The photophysical properties of the BODIPY derivative 2 were investigated in acetonitrile solutions. The compound showed an intense absorption band $(\log \varepsilon=4.89)$ at $492 \mathrm{~nm}$. Upon excitation at $460 \mathrm{~nm}$, the compound showed an intense emission band at $506 \mathrm{~nm}$ (Figure 1). The relative fluorescence quantum yield, determined by using Rhodamine $6 \mathrm{G}$ in ethanol as standard $\left(\Phi_{F}=0.95\right)$, was found to be low $\left(\Phi_{F}=0.024\right)$. The small quantum yield measured could be ascribed to a carbonyl electron-withdrawing effect exerted by the formyl group linked to the BODIPY core [11]. 

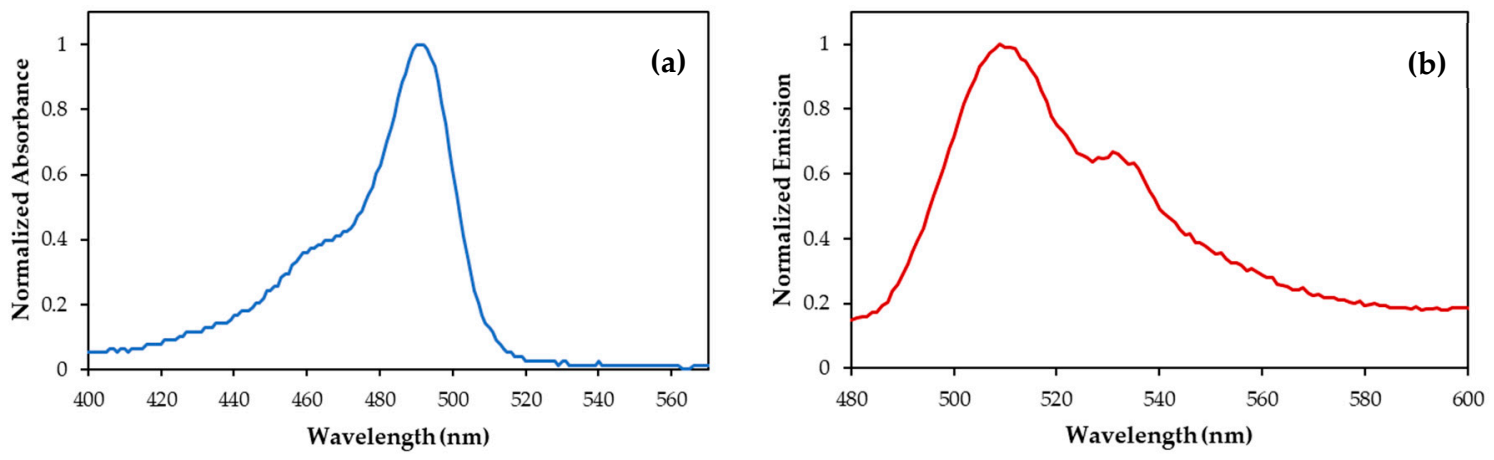

Figure 1. Normalized UV-visible spectrum (a) and fluorescence spectrum (b) of BODIPY derivative 2 in acetonitrile.

\subsection{Chemosensing Studies of BODIPY Derivative 2 and Spectrophotometric Titration}

Evaluation of the BODIPY derivative $\mathbf{2}$ as colorimetric chemosensor was carried out in acetonitrile solutions, in the presence of several cations. The preliminary study was carried out by the addition of up to 50 equivalents of each cation to the solution of the compound. It was observed that the BODIPY derivative displayed a color change only upon interaction with $\mathrm{Fe}^{3+}$, from light orange to light grey (Figure 2).

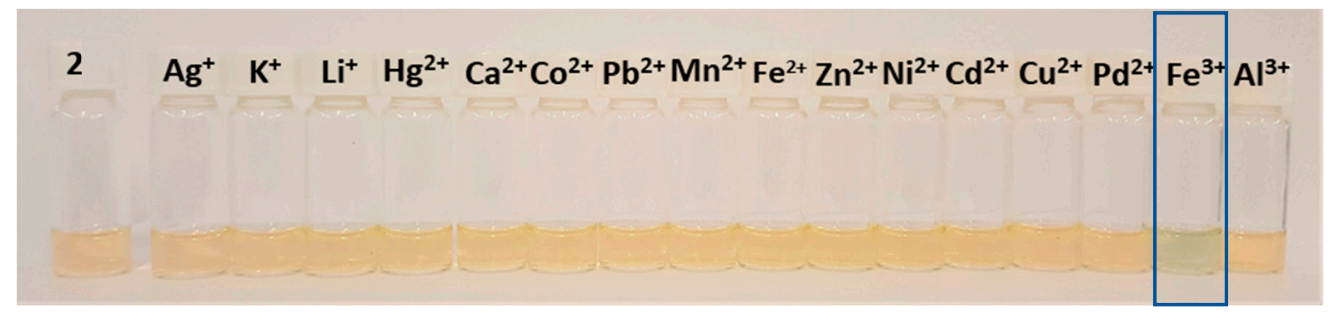

Figure 2. Color changes of BODIPY derivative $2\left(1 \times 10^{-5} \mathrm{M}\right)$ in the presence of 50 equivalents of several cations, in acetonitrile.

The spectrophotometric titration of BODIPY derivative 2 was performed in acetonitrile with $\mathrm{Fe}^{3+}$ as a result of the preliminary study, which revealed the highly selective colorimetric response towards this cation. The UV-visible spectra revealed that the intensity of the absorption band at 491 $\mathrm{nm}$ decreased progressively upon the addition of the cation. The number of $\mathrm{Fe}^{3+}$ equivalents to achieve a plateau was at about 15 equivalents (Figure 3 ).

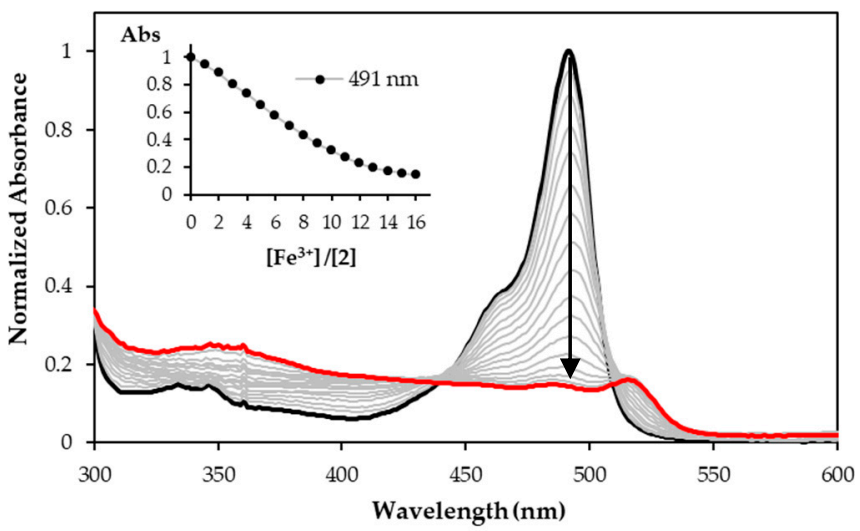

Figure 3. Spectrophotometric titration of BODIPY derivative 2 with addition of increasing amounts of $\mathrm{Fe}^{3+}$ in acetonitrile. The inset represents the normalized absorbance at $491 \mathrm{~nm}\left([2]=1 \times 10^{-5} \mathrm{M}\right)$. 


\section{Conclusions}

The BODIPY derivative 2 functionalized at position 2 with a formyl group was synthesized in good yield (57\%) through Vilsmeier-Haack reaction. The compound was characterized by the usual spectroscopic techniques, and the photophysical properties were also determined.

The selective recognition of $\mathrm{Fe}^{3+}$ in acetonitrile solution among several cations was obtained with the novel BODIPY derivative 2 through a color change from light orange to light grey, making this compound suitable as a colorimetric chemosensor for $\mathrm{Fe}^{3+}$.

Funding: This research was funded by the Foundation for Science and Technology (FCT) for financial support to CQ/UM (UID/QUI/00686/2016 and UID/QUI/00686/2019) and project PTDC/QUI-COL/28052/2017. Thanks are also due to Fundação para a Ciência e Tecnologia (Portugal) for financial support to the Portuguese NMR Network (PTNMR, Bruker Avance III 400-Univ. Minho).

Conflicts of Interest: The authors declare no conflict of interest.

\section{References}

1. Boens, N.; Verbelen, B.; Dehaen, W. Postfunctionalization of the BODIPY Core: Synthesis and Spectroscopy. Eur. J. Org. Chem. 2015, 2015, 6577-6595, doi:10.1002/ejoc.201500682.

2. Loudet, A.; Burgess, K. BODIPY Dyes and their Derivatives: Syntheses and Spectroscopic Properties. Chem. Rev. 2007, 107, 4891-4932, doi:10.1021/cr078381n.

3. Farina, M.; Avila, D.S.; Da Rocha, J.B.T.; Aschner, M. Metals, Oxidative Stress and Neurodegeneration: A Focus on Iron, Manganese and Mercury. Neurochem. Int. 2013, 62, 575-594, doi:10.1016/j.neuint.2012.12.006.

4. Kaur, B.; Kaur, N.; Kumar, S. Colorimetric Metal Ion Sensors-A Comprehensive Review of the Years 2011-2016. Coord. Chem. Rev. 2018, 358, 13-69, doi:10.1016/j.ccr.2017.12.002.

5. Presti, M.L.; Martínez-Máñez, R.; Ros-Lis, J.V.; Batista, R.M.F.; Costa, S.P.G.; Raposo, M.M.M., Sancenón, F. A Dual Channel Sulphur-containing Macrocycle Functionalised BODIPY Probe for the Detection of $\mathrm{Hg}(\mathrm{II})$ in Mixed Aqueous Solution. New J. Chem. 2018, 42, 7863-7868, doi:10.1039/c7nj04699e.

6. Esteves, C.I.C.; Ferreira, R.C.M.; Raposo, M.M.M.; Costa, S.P.G. New Fluoroionophores for Metal Cations Based on Benzo[d]Oxazol-5-yl-Alanine Bearing Pyrrole and Imidazole. Dyes Pigments 2018, 151, 211-218, doi:10.1016/j.dyepig.2017.12.040.

7. Batista, R.M.F.; Costa, S.P.G.; Raposo, M.M.M. Selective colorimetric and fluorimetric detection of cyanide in aqueous solution using novel heterocyclic imidazo-anthraquinones. Sens. Actuators B Chem. 2014, 191, 791-799, doi:10.1016/j.snb.2013.10.030.

8. Pinto, S.C.S.; Gonçalves, R.C.R.; Costa, S.P.G.; Raposo, M.M.M. (University of Minho, Braga, Portugal). Personal communication, 2019.

9. Montalti, M.; Credi, A.; Prodi, L.; Gandolfi, M.T. Handbook of Photochemistry, 3rd ed.; CRC Press: Boca Raton, FL, USA, 2006.

10. Demas, J.N.; Crosby, G.A. Measurement of photoluminescence quantum yields. Rev. J. Phys. Chem. 1971, 75, 991-1024, doi:10.1021/j100678a001.

11. Valeur, B.; Berberan-Santos, M.N. Molecular Fluorescence: Principles and Applications; Wiley-VCH: Weinheim, Germany, 2012. 